\title{
Chemotherapeutic Trial of Combined Capreomycin and Diasone*
}

\author{
J. C. HATHAWAY† \\ University of Hawaii School of Medicine, Honolulu, Hawaii, U.S.A.
}

\section{INTRODUCTION}

In Hawaii, as in all areas where thelepromatous type of leprosy is common, there is a proportion of patients that do not respond well to sulphone therapy. From Hale Mohalu Hospital, Hansen's Disease Faculty for the State of Hawaii, 5 of these patients with lepromatous leprosy who had been receiving sulphone treatment for many years - 4 of them since 1946 and 1 since 1947 — and had had both high- and low-dosage treatment were selected for the trial. In all of these cases sulphone resistance was suspected. It was therefore decided to try them on combined therapy with Capreomycin and Diasone, giving Capreomycin, $1 \mathrm{~g}$ intramuscularly 6 times a week and Diasone 0.15 g 3 times a week. Capreomycin was chosen (Black et al., 1962; Colestos and Oriot, 1964; Gunella et al., 1964; Stark et al., 1962) because it had been investigated by Shepard (1964) using the mouse footpad method and appeared to have a reasonable chance of success. Diasone (sulfoxone sodium) was chosen because these patients appeared to tolerate the sulphone drug in small doses better than other sulphones that they had taken. It was decided to use combined therapy because of better patient acceptance, as well as the chance for better results. No attempt has been made in this study to compare this combination with other methods of treatment.

In all 5 cases the leprosy was of the lepromatous (LL) type. The original diagnosis in each case had been made by experienced leprologists

\footnotetext{
*Received for publication February, 1970.

†Medical Director, Hale Mohalu Hospital, State of Hawaii Department of Health, Pearl City, Hawaii 96782, and Clinical Associate Professor of Tropical Medicine, University of Hawaii School of Medicine, Honolulu, Hawaii 96816.
}

by clinical examination, biopsy, and the scrapedincision technique. All had had several subsequent biopsy and numerous skin-smear examinations. All had been under the treatment of experienced leprologists for years; all were lepromin negative. During the course of this study, also, all the patients were seen once a month by an experienced independent leprologist (Dr. Claude Caver) (Pettit and Rees, 1967; Waters et al., 1967).

\section{LABORATORY DATA}

Complete blood counts, consisting of determination of hematocrit, white blood cell count, haemoglobin and differential values were done on all cases before beginning the study, then once a month for 6 months, and later at 2 -monthly intervals; these showed no deviations from the normal range and no changes of significance. The urine was analysed before the study and once a month for 6 months, and thereafter at 2-monthly intervals; no marked deviation from normal was found and no significant changes occurred.

Blood urea nitrogen levels and thymol turbidity tests, carried out before the beginning of the study and also every 3 months, all gave results within normal limits.

Sulphone blood levels, determined monthly, showed a variation of between 0.03 and $1.3 \mathrm{mg}$ per $100 \mathrm{ml}$, these levels being considered satisfactory. Chest X-ray examinations made before the study started and again 6 months later all showed normal results. An audiometer test was made every 3 months; in all cases the results stayed within normal limits.

Biopsy indices were not done. Skin smears were taken by the standard scraped-incision 
TABLE 1

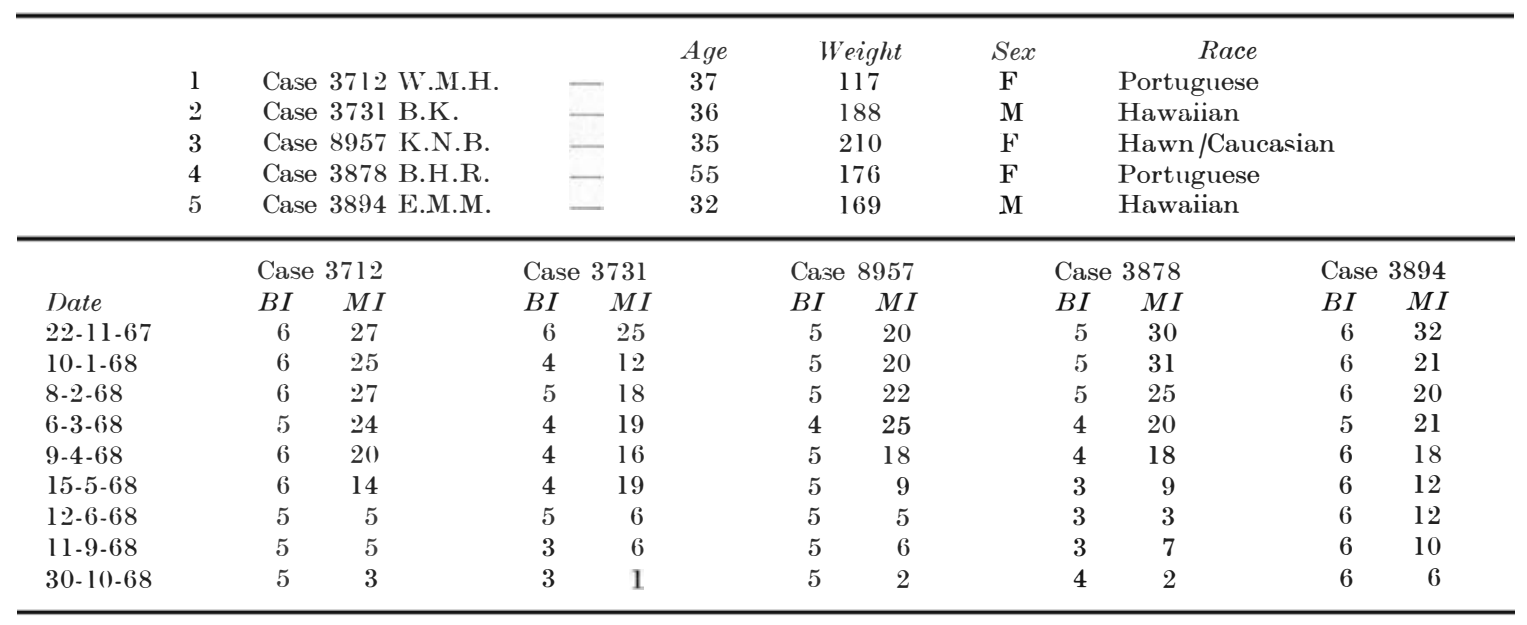

technique before beginning the study, and then every month for 6 months and subsequently every 2 months; staining was by the ZiehlNeelsen technique, and all slides were examined by the same experienced technician. Since all cases showed generalized heavy infiltration, the ear was chosen as the site for taking the skin smears. The Bacterial Index (BI) was used as follows:

$6+$ Many clumps of bacilli in an average microscopic field (over 1000 bacilli).

$5+$ 100-1000 bacilli in an average microscopic field.

$4+$ 10-100 bacilli in an average microscopic field.

$3+\quad 1-10$ bacilli in an average microscopic field.

$2+1-10$ bacilli on average in 10 microscopic fields.

$1+1-10$ bacilli on average in 100 microscopic fields.

The Morphological Index (MI) is the percentage of solid staining forms. Table 1 shows the results obtained.

It will be noted that the BI in each patient changed very little but in every case the MI fell by the greatest amount between the fourth and sixth months.
In 4 out of the 5 patients, clinical improvement paralleled the above laboratory data to some extent, showing considerable improvement at 6 months and more at the end of a year. The fifth patient, 3894, began to show small leprous nodules about the sixth month, but these gradually regressed.

One patient, 3731, developed a dermatitis after 9 months. This cleared within one month during which Capreomycin was discontinued and Benadryl given. At the end of a month, Capreomycin was resumed and Benadryl continued without recurrence of the dermatitis. At the end of a year another patient asked that the Capreomycin be discontinued temporarily because of soreness at the site of injection. No other ill-effects were noted.

\section{CONCLUSIONS AND SUMMARY}

1. Because Capreomycin needs to be given almost daily by intramuscular injection, its use would not seem to be practicable except in cases that do not respond to sulphones.

2. Capreomycin and Diasone in combination appear to be worthy of further, more extensive trial in cases that have not responded to sulphones.

3. Any ill-effects from this drug combination appear to be minimal. 


\section{REFERENCES}

BLACK, H. R., GRIFFITH, R. S. and BRICKLER, J. F. (1962). Preliminary laboratory studies with Capreomycin. In Antimicrobial Agents and Chemotherapy, pp. 522-529 American Society for Microbiology, Ann Arbor, Mich.

Colestsos, P. J. and oriot, E. (1964). Study of antibacterial activity in vitro of Capreomycin. Rev. Tuberc. et Pneumol., (Paris), 23, 413.

GUNella, G., Gabrielli, A., Diperna, A., Pivirotto, I. TERMine, A. and PETrElla, A. (1964). Antibacterial activity of Capreomycin. Riv. Pat. Clin. Tuberc., 37, 705 .
Pettit, J. H. S. and Rees, R. J. W. (1967). Chemotherapeutic trials in leprosy. Int. J. Lepr. 35, 140.

SHEPARD, C. C. (1964). Capreomycin: activity against experimental infection with Mycobacterium leprae. Science 146, 403.

STARK, W. M., HIGGENS, C. E., WOLFE, I. M., HOEHN, M. M. and MCGUIRE, J. M. (1962). Capreomycin, a new antimycobacterial agent produced by Streptomyces capreolus sp. n. In Antimicrobial Agents and Chemotherapy, p. 596. American Society for Microbiology, Ann Arbor, Mich.

WATERS, M. F. R., REES, R. J. W. and SUTHERLAND, I. (1967). Chemotherapeutic trials in leprosy. Int. J. Lepr. 35, 311 . 